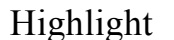

\title{
Unraveling the Dynamics of Antibody-Antigen Interaction by DNA Origami
}

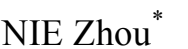

State Key Laboratory of Chemo/Bio-sensing and Chemometrics, College of Chemistry and Chemical Engineering, Hunan Provincial Key Laboratory of Biomacromolecular Chemical Biology,

Hunan University, Changsha 410082, P. R. China
\end{abstract}

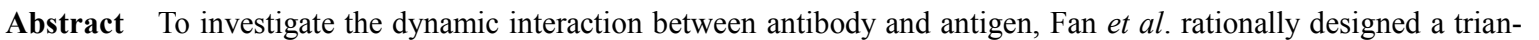

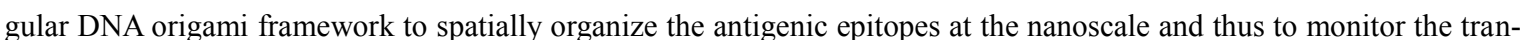

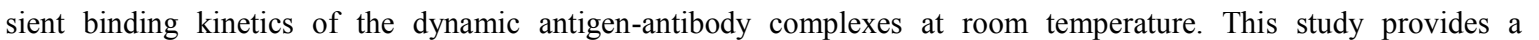

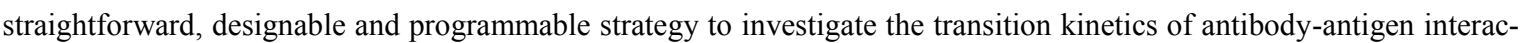

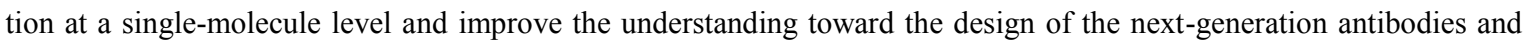

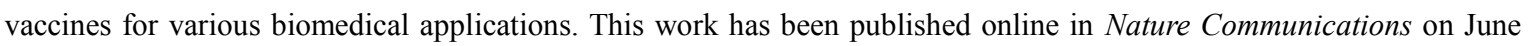
पाणाणाण
\end{abstract}

$\square$

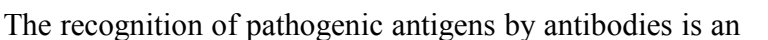

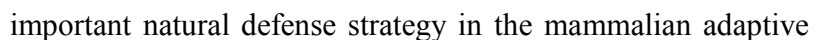

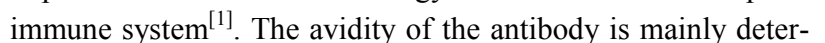

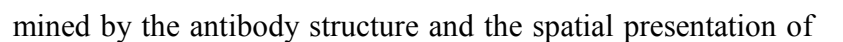

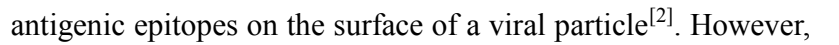

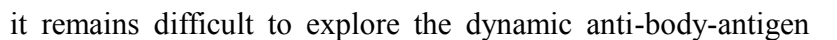

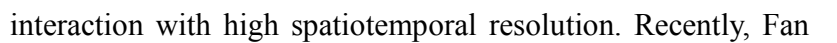

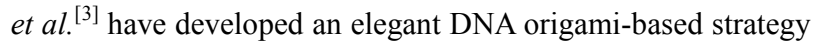

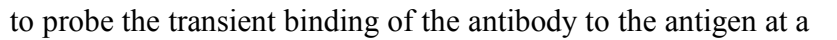

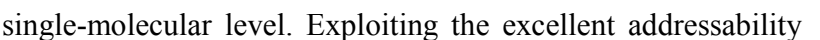

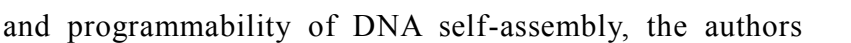

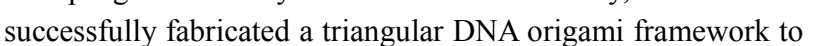

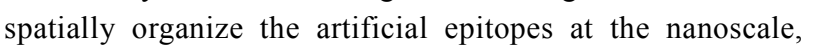

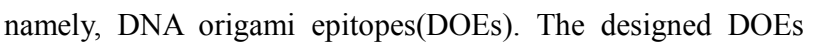

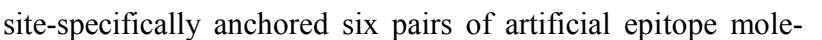

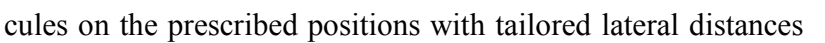

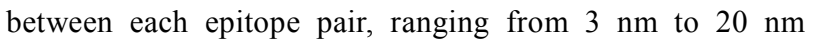

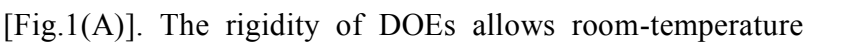

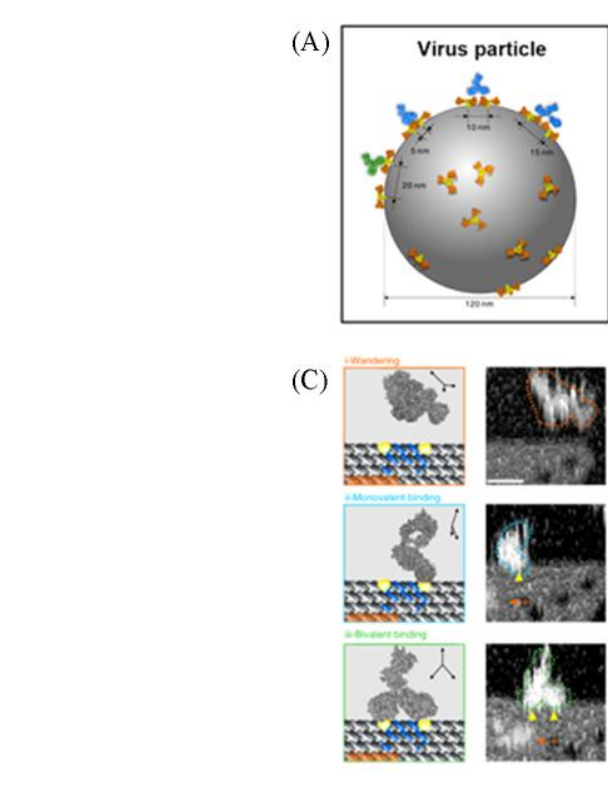

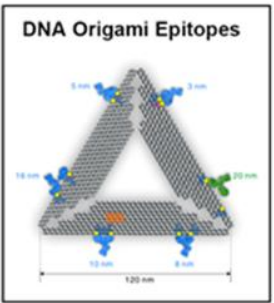

(D)

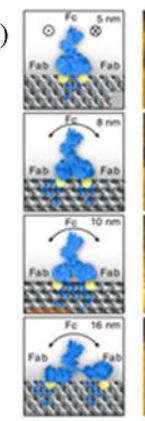

(B)
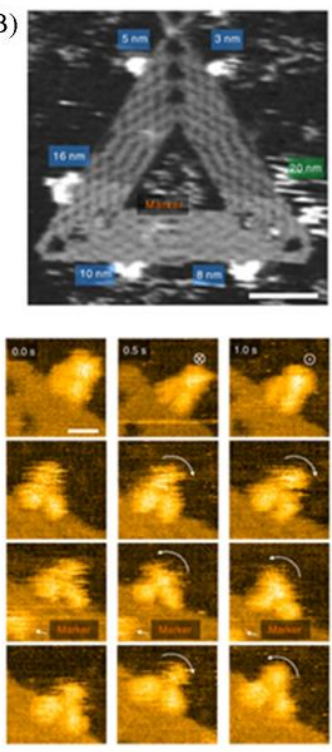

Fig.1 Schematic illustration of epitope spikes on the surface of a viral particle and DOEs for IgG capture and binding(A), peak force-AFM image for DOEs-captured $\operatorname{IgGs(B),~schematic~of~the~three-stage~}$ binding process(left) and corresponding HS-AFM images(right)(C), and distinct conformations of single IgG captured by DOEs with designed distances, and schematic illustration(left) and snapshot HS-AFM images(right)(D) ${ }^{[3]}$

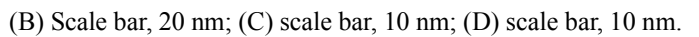




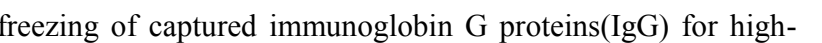

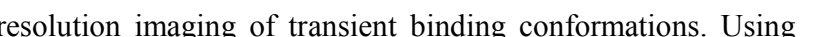

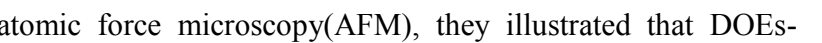

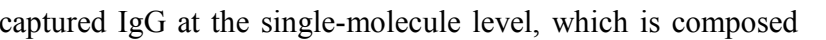

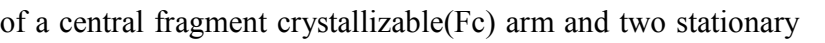

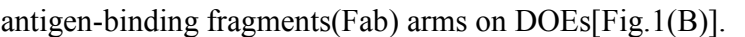

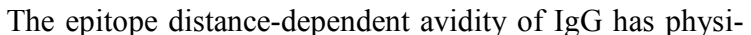

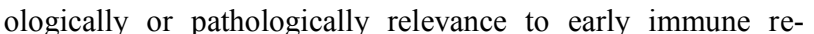

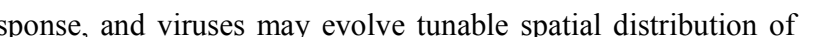

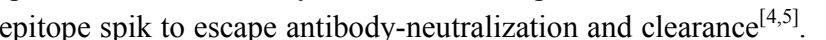

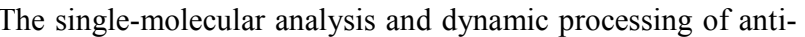

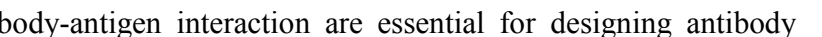

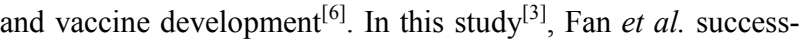

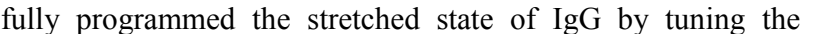

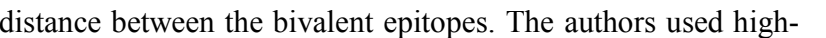

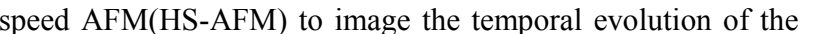

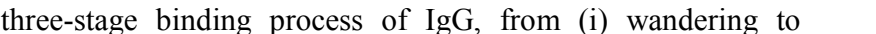

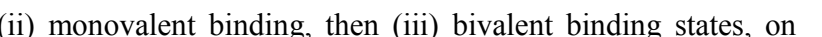

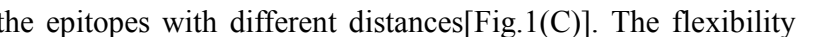

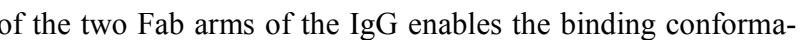

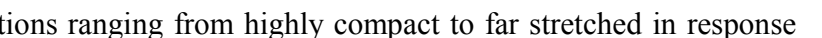

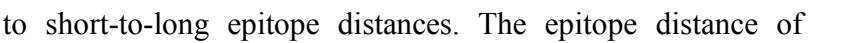

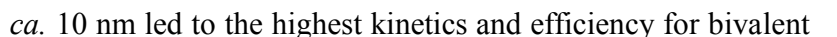

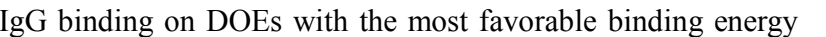

पापाणापाणा

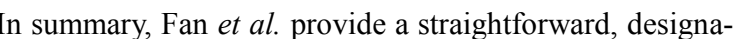

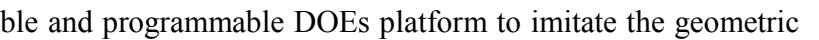

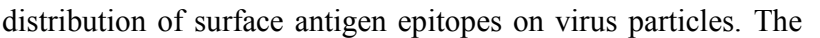

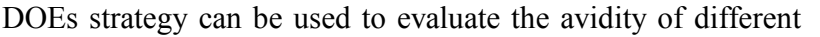

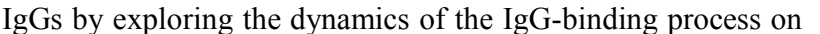

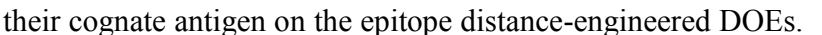

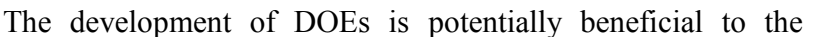

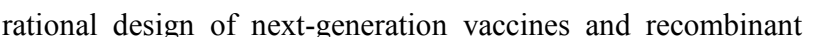

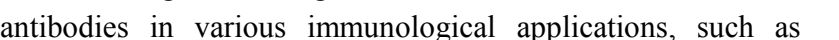

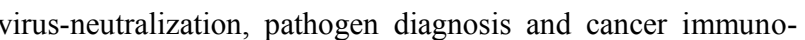
एणाणाण

\section{References}

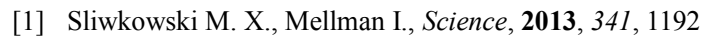

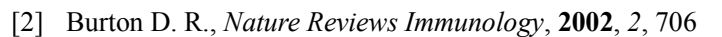

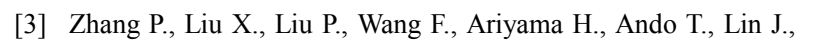

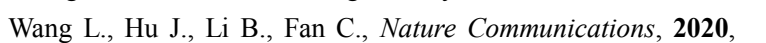

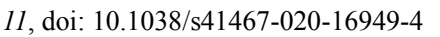

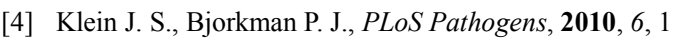

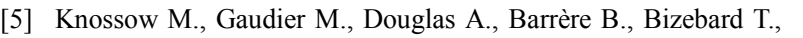

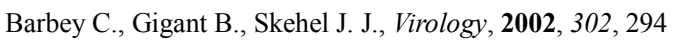

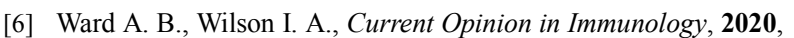
65 एा1 